\title{
Multidisciplinary programs for obesity treatment in Brazil: A systematic review
}

\author{
Programas de tratamento multiprofissional \\ da obesidade no Brasil: uma
}

revisão sistemática

\author{
Anselmo Alexandre MENDES ${ }^{1}$ \\ Ana Sílvia Degasperi IEKER ${ }^{2}$ \\ Talitha Fernandes de CASTRO² \\ Ademar AVELAR ${ }^{1}$ \\ Nelson NARDO JÚNIOR ${ }^{1}$
}

\section{A B S T R A C T}

This study aimed to conduct a systematic review of publications addressing the multidisciplinary treatment of obesity in Brazil and analyze their main results. A search was conducted in the databases SciELO, Lilacs, and Pubmed/Medline using the following search terms: 'obesidade', 'intervenção', 'tratamento', 'Brasil', for the search in Portuguese, and 'obesity', 'intervention', 'treatment', 'Brazil', for the search in English. Based on these terms, the following combination of words was used: 'Intervenção multiprofissional da obesidade', 'tratamento multidisciplinar da obesidade, tratamento multiprofissional da obesidade' and 'multidisciplinary obesity intervention', 'multidisciplinary obesity treatment', 'Multiprofessional obesity treatment'. Inclusion criteria were as follows: original studies carried out in Brazil involving human beings and that reported an intervention including two or more health care professionals. Articles published between January 2005 and July 2015 were analyzed independently by two reviewers. At the end of the analysis, out of 355 articles initially selected, 26 met all inclusion criteria. The following results were found: 23 studies involved children and adolescents and 03 involved adults 20-60 years of age. It was also found that the 26 studies analyzed had an impact on anthropometric parameters, 10 on physical fitness parameters, 16 on biochemical parameters, 10 on the reduction in comorbidities, 6 on nutritional parameters, and 4 on the psychological/social aspects. Based on evidence presented in the studies reviewed, it can be said that the multidisciplinary treatment for obesity greatly contributed to the reduction in the anthropometric indicators, especially BMI and the biochemical, social, and psychological parameters. Thus, these findings demonstrate that there is a need to expand the range of this type of treatment since it has proven to be effective in the fight against obesity and its comorbidities.

Keywords: Behavior therapy. Obesity. Physical Education and training.

\footnotetext{
1 Universidade Estadual de Maringá, Curso de Educação Física, Departamento de Educação Física. Av. Colombo, 5790, Jardim Universitário, 87020-900, Maringá, PR, Brasil. Correspondência para/Correspondence to: AA MENDES. E-mail: <profanselmol@gmail.com>.

2 Universidade Estadual de Maringá. Programa de Pós-Graduação em Educação Física. Maringá, PR, Brasil.
} 


\section{RE S U M O}

Este estudo teve como objetivo investigar publicações sobre o tratamento multiprofissional da obesidade no Brasil e seus principais resultados. A busca sistemática foi realizada nas bases de dados SciELO, Lilacs e Pubmed/Medline. Foram constituídos os seguintes termos de procura: 'obesidade', 'intervenção', 'tratamento' e 'Brasil', para língua portuguesa, e 'obesity', 'intervention', 'treatment' e 'Brazil', na versão inglesa. A partir disso, foram constituídos os seguintes agrupamentos para a busca: Intervenção multiprofissional da obesidade, multidisciplinary obesity intervention, multidisciplinary obesity treatment, Multiprofessional obesity treatment, tratamento multidisciplinar da obesidade, tratamento multiprofissional da obesidade. Os critérios de inclusão foram: artigos originais de pesquisas realizadas no Brasil com seres humanos e que tivessem feito uma intervenção com dois ou mais profissionais da área de saúde. Foram analisadas por dois revisores, de forma independente, publicações entre os anos de 2005 e julho de 2015. Ao final das análises, de um total de 355 artigos selecionados, 26 estudos atenderam a todos os critérios de inclusão. Foram constatados os seguintes desfechos: 23 estudos eram com crianças e adolescentes e 03 com adultos de 20 a 60 anos. Resultados: No total, 26 estudos analisados tiveram impacto nos parâmetros antropométricos, 10 nos parâmetros de aptidão física, 16 nos parâmetros bioquímicos, 10 na diminuição das comorbidades, seis nos parâmetros nutricionais e quatro nos aspectos psicológicos/sociais. A partir das evidências apontadas pelas obras, o tratamento multiprofissional da obesidade se mostrou impactante na redução dos indicadores antropométricos, principalmente na diminuição do índice de massa corpórea e dos parâmetros bioquímicos, sociais e psicológicos. Assim, evidencia-se a necessidade de ampliação desse tipo de tratamento pela sua efetividade no combate à obesidade e suas comorbidades.

Palavras-chave: Terapia comportamental. Obesidade. Educação física e treinamento.

\section{INTRODUCTION}

Obesity has become a major public health problem in both developed and developing countries. It is a chronic disease with a multifactorial etiology, and it is characterized by an accumulation of excess body fat ${ }^{1}$.

Prevalence of obesity has increased in all populations, regardless of gender, race, age, and social class. It is a pathological state of major concern because excessive weight gain can lead to comorbidities such as cardiovascular, musculoskeletal, metabolic, and respiratory diseases ${ }^{2}$. These comorbidities account for $72 \%$ of the deaths in the country ${ }^{3}$, and, as claimed by the authors of the latter study, the higher the level of education, the lower the overweight and obesity rates.

According to the data reported by Vigitel ${ }^{3}$ (a telephone-based surveillance system for the monitoring of Risk and Protective Factors for Chronic Diseases), more than half (52.0\%) of the population in Brazil are overweight or obese; and men have the highest rate $56.5 \%$, while women account for $49.1 \%$. In the previous year, the prevalence was $50.8 \%$, and if compared to 2006 , the difference is even greater since the first Vigite $^{3}$ survey was conducted in 2006, when the rate was $43.0 \%$.

Vigitel $^{3}$ data also revealed that obesity remained stable (17.9\%) in 2014 as compared to $2013(17.5 \%)$, with a prevalence of $17.6 \%$ in men and $18.2 \%$ in women.

This disease does not affect adults only. According to Instituto Brasileiro de Geografia e Estatística (IBGE, Brazilian Institute of Geography and Statistics) data, overweight and obesity are also common among children aged $\geq 5$ years in all Brazilian regions, regardless of social class 4 .

From the above discussion, obesity can be considered a complex public health challenge. Multidisciplinary treatments have proven to be effective and efficient against this disease in terms of cardiometabolic, anthropometric, psychological, and social parameters among others; thus, it can directly or indirectly combat its comorbidities and consequences. This field has advanced significantly in recent years due to international multidisciplinary studies such as the Diabetes Prevention Program (DPP) and the Action for 
Health in Diabetes (AHEAD). These studies demonstrated the efficacy of well-structured multidisciplinary programs in decreasing incidence of Diabetes Mellitus (DM) and delaying the onset of cardiovascular disease in diabetic patients, respectively. The primary goal of this type of multidisciplinary treatment is changes in behavior for the adoption of an active and healthy lifestyle $\mathrm{e}^{5-10}$.

Despite the unprecedented advances in research to prevent this disease, there are few studies addressing multidisciplinary treatment based on behavior changes and the monitoring of the research centers, the populations receiving treatment, the number of people being treated, and the research outcomes.

\section{METHODS}

The objective of this study was to carry out a systematic review of relevant studies on the multidisciplinary approach to the treatment of obesity in Brazil, using the databases Scientific Electronic Library Online (SciELO), Literatura Ciêntifica e Técnica da América Latina e Caribe (Lilacs), and Pubmed to select articles published between January 2005 and July 2015 and analyze their results.

The systematic search was conducted in the virtual libraries SciELO, Lilacs and Pubmed between September 2015 and November 2015. SciELO and Lilacs, are databases of specialized collections of Latin American Scientific Journals. Pubmed comprises over 20 million international publications related to the field of health.

The search terms in Portuguese were: obesidade, intervenção, tratamento, and Brasil; the search terms in English were: obesity, intervention, treatment, and Brazil.

Based on these descriptors, the following combination of words was used: Intervenção multiprofissional da obesidade, tratamento multidisciplinar da obesidade, tratamento multiprofissional da obesidade and multidisciplinary obesity intervention, multidisciplinary obesity treatment, Multiprofessional obesity treatment.

The inclusion criteria were: studies that were published between January 2005 and July 2015, addressing common obesity interventions involving participants who did not use weight loss drugs, who had not undergone bariatric surgery, and who had undergone a multidisciplinary treatment for obesity with professionals from at least two different health areas. There was no manual search of the reference lists of the selected studies.

The steps for selection or exclusion of studies were as follows: after searching the databases using the descriptors and the criteria described above, the first step included careful reading of the titles and abstracts, and the second step consisted of reading and analysis of the full text of the articles.

Two researchers performed the articles search and analysis individually and independently, and the discrepancies were discussed and resolved in order to decide on the final selection of the articles retrieved.

The vocabulary thesaurus Health Sciences Descriptors (DeCS) and the Medical Subject Headings. National Library of Medicine (MeSH), were used to identify the most appropriate descriptors on this topic in different languages.

Subsequently, we developed the first draft of the guide to conducting the search of the relevant articles including: authors' names, year of publication, place where the study was carried out, sample size, participants' age (Table 1 classification criteria), length of the intervention. The second draft included the main outcomes of the articles selected in the following order: Anthropometric, physical fitness, biochemical, nutritional, and psychological outcomes.

\section{RES U L T S}

Figure 1 shows the flowchart for article selection. With regard to the type of intervention 
used in each study, one of the inclusion criteria was having carried out more than one health intervention (described in the methodology section).

In the first step of the search in the Pubmed database using the descriptors, 218 articles were identified, and 16 fulfilled the inclusion criteria. Of the 202 excluded articles, 130 did not fulfill the criteria because they did not involve a multidisciplinary treatment, 72 they were duplicated. After careful reading, one article was excluded because it was duplicated, and thus 15 articles related to obesity and multidisciplinary treatment remained for final analysis and comprehensive full text reading.

Searching the Lilacs database in Portuguese, 22 articles were initially selected. After analysis, 18 articles were excluded, because

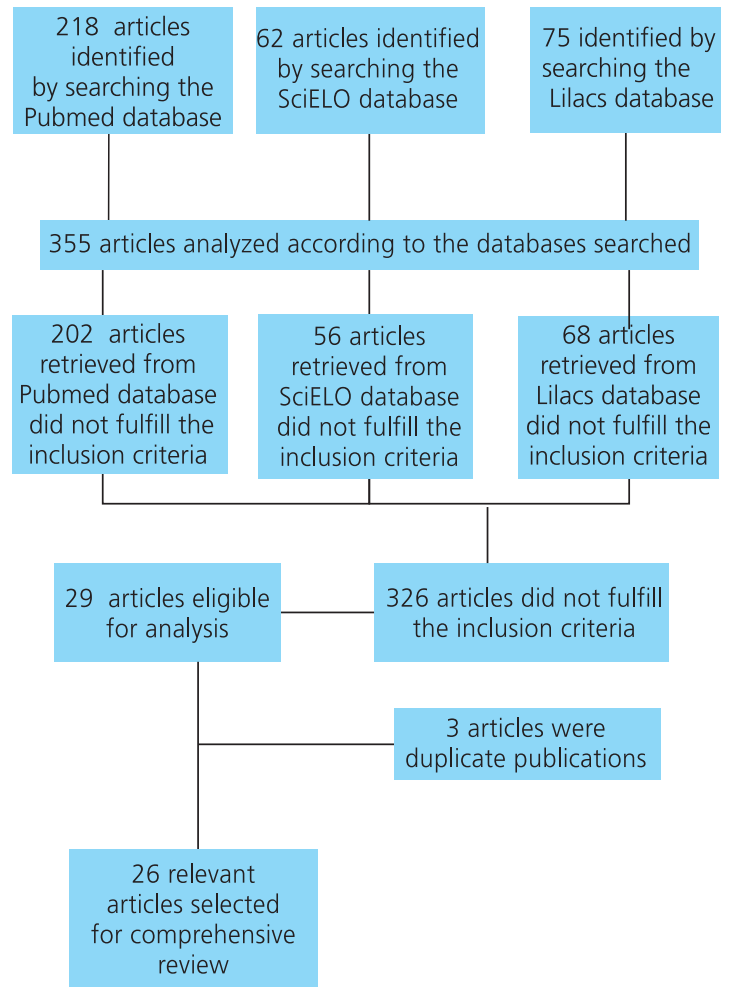

Figure 1. Flowchart including information per database found in the systematic review on multidisciplinary programs for obesity treatment in Brazil: a systematic review of the literature between 2005 and July 2015. they did not involve an interdisciplinary intervention. Therefore, 4 studies were selected for the next step. In the search in English, 53 articles were identified, and after analysis, only 3 articles remained. Of the 50 articles excluded, 25 they were duplicated, and 25 were duplicate copies. A total of 7 articles were selected in both languages.

Similarly, in the search in the SciELO database in Portuguese, 11 articles fulfilled the inclusion criteria, but only 3 were used in the final analysis; 8 studies were excluded because they didn't fit the protocol of the study. Fifty-one articles were identified in the search in English, but only three were selected; after subsequent analysis, only 1 article remained because 2 were duplicated. Of the 48 articles excluded, 48 did not fulfill the criteria because they did not involve a multidisciplinary treatment, or were related to bariatric surgery.

Table 1 shows general information about the 26 articles selected in this systematic review, sorted according to the year of publication. Out of these 26 articles, there was only 1 article published in the years 2005, 2006, and 2007, 2 published in 2009, 4 in 2010, 3 in 2011, 4 in 2012, 7 in 2013, 2 in 2014, and 1 in 2015. There were 23 articles involving participants under 20 years of age $(n=1023)$ and 3 articles with 349 participants aged 20-60 years. As for the distribution of the participants according to gender, there were 423 females and 324 males, and 8 studies did not include the participants' distribution according to gender, totaling 625 people; 9 studies did not report the gender composition of their sample.

Of the 26 articles selected, 13 were carried out in the state of São Paulo ${ }^{5,11}$ dexondania, 5 in Paraná9,12,21,31, 3 in Pernambuco 17,19,20, 2 in Rio Grande do Sul 8,18, 1 in Santa Catarina ${ }^{25}, 1$ in Minas Gerais $^{33}$, and 1 in the Federal District ${ }^{29}$.

All interventions were monitored by a physical education professional or a physiotherapist ${ }^{33}$ and involved a physical exercise program. The participation of a nutritionist in all 


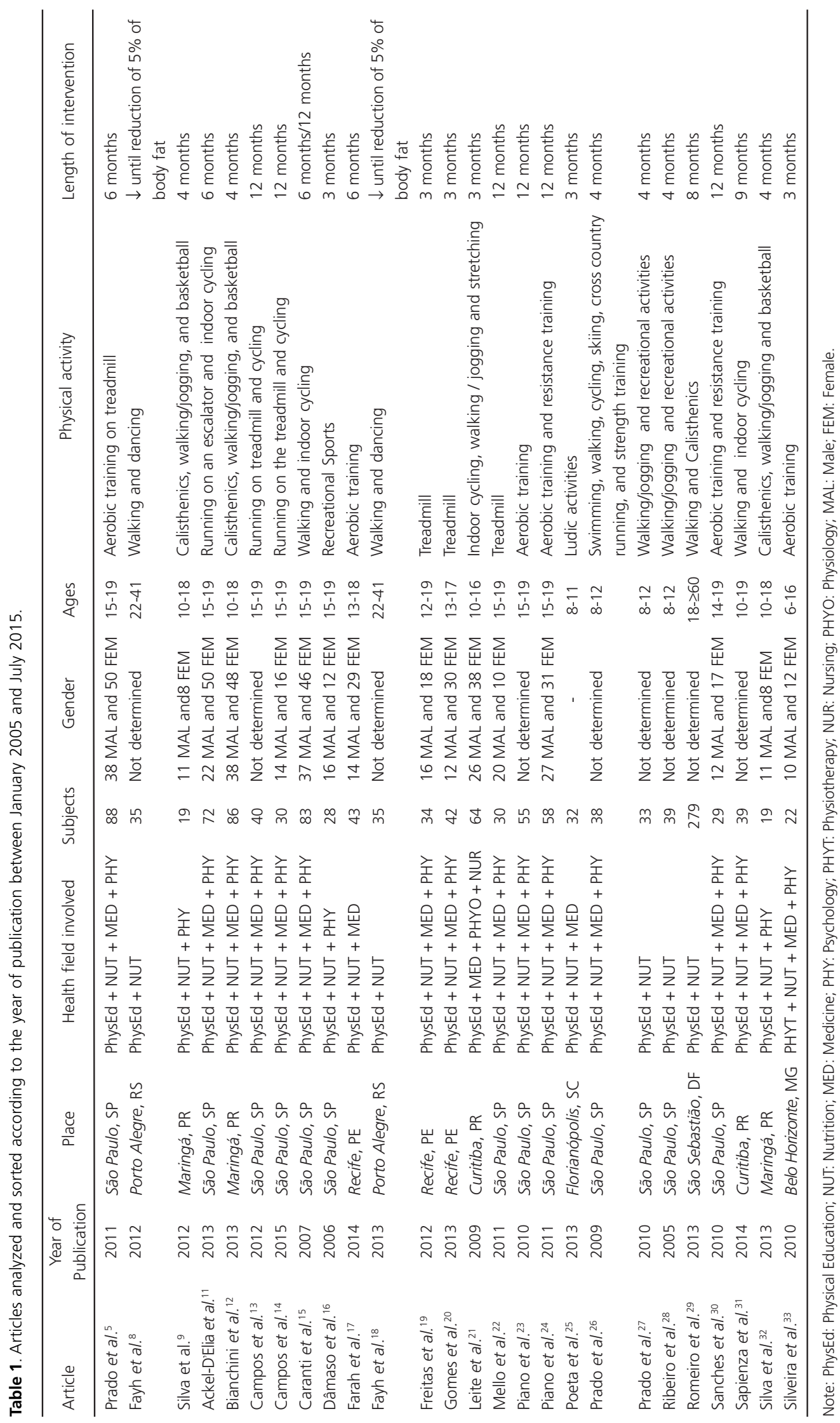




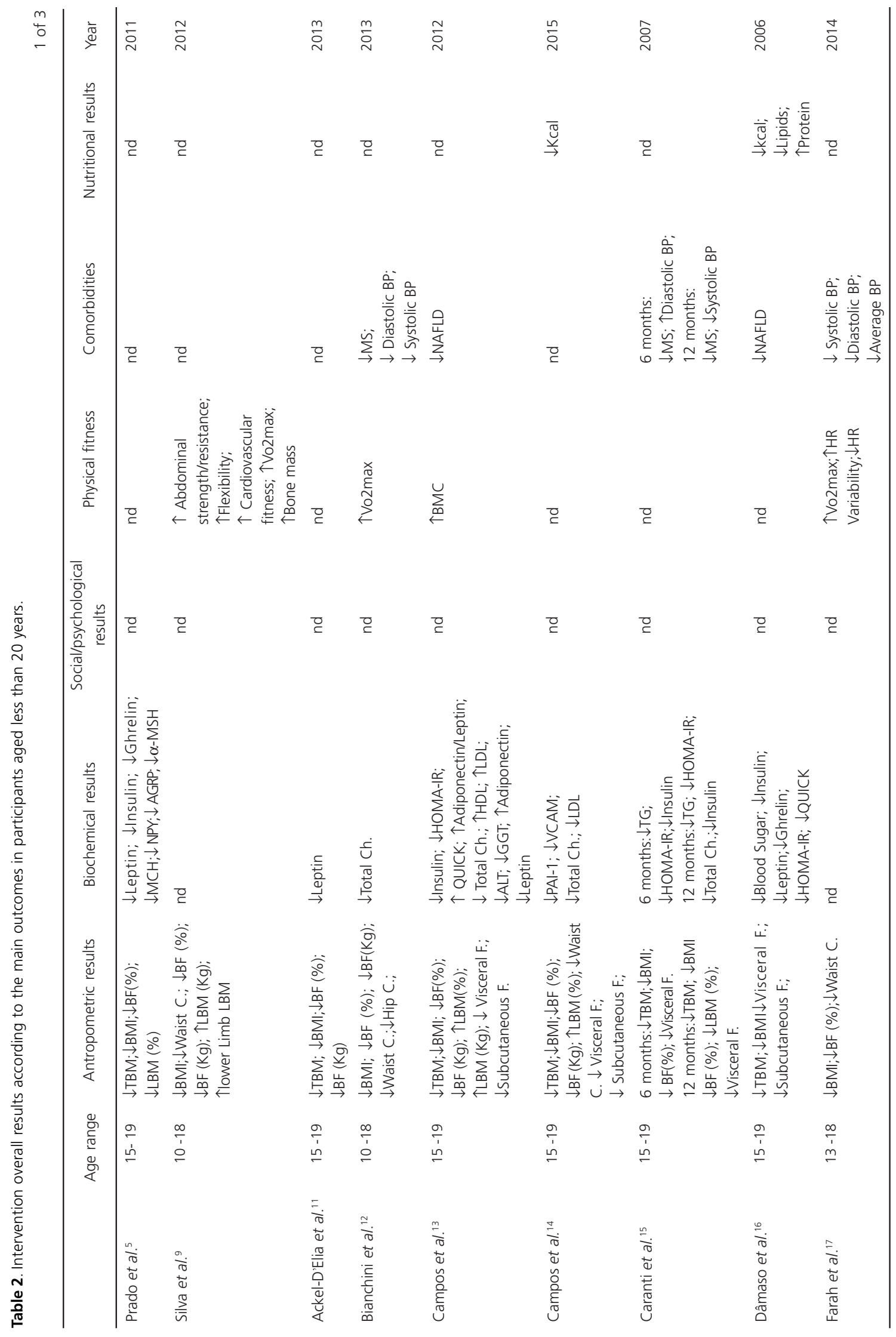




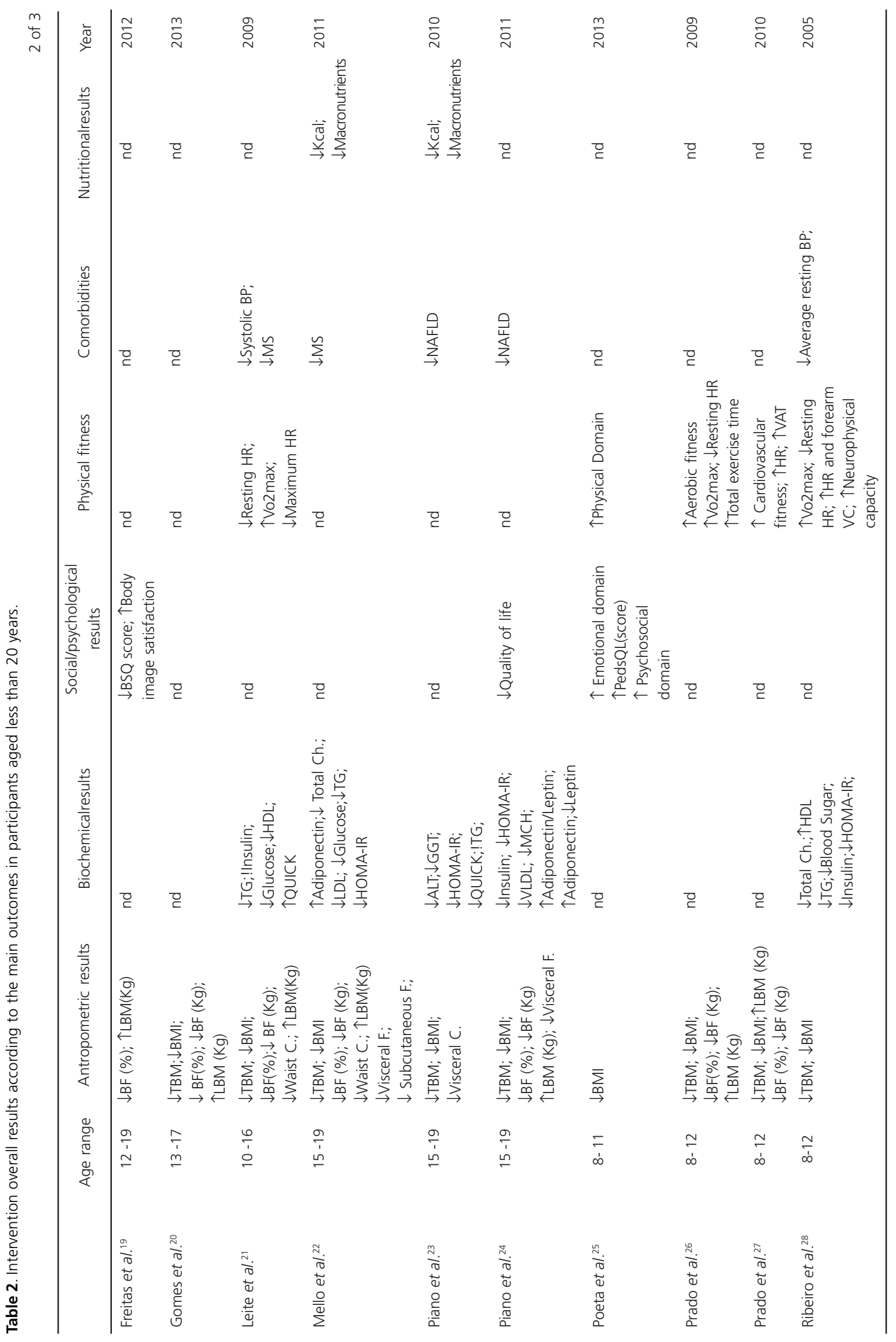




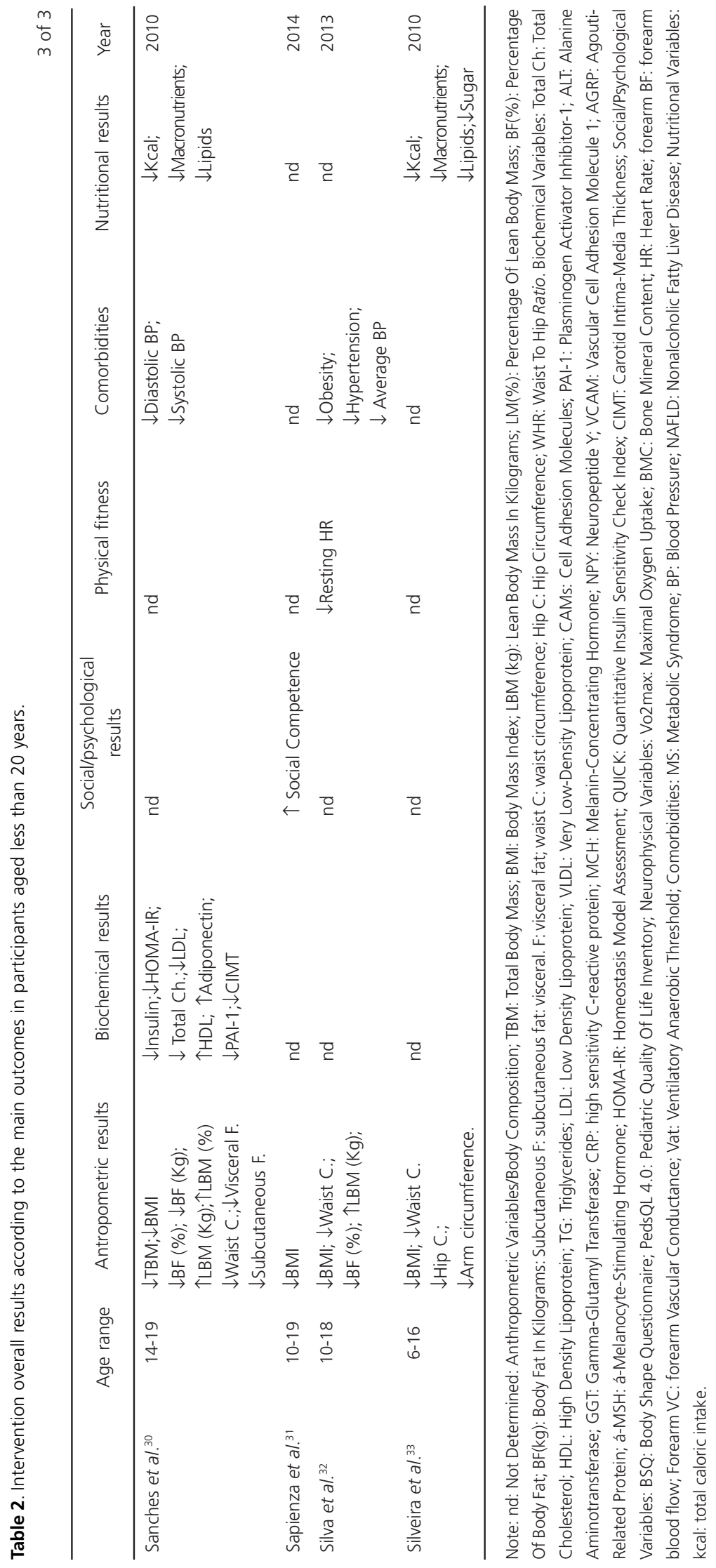




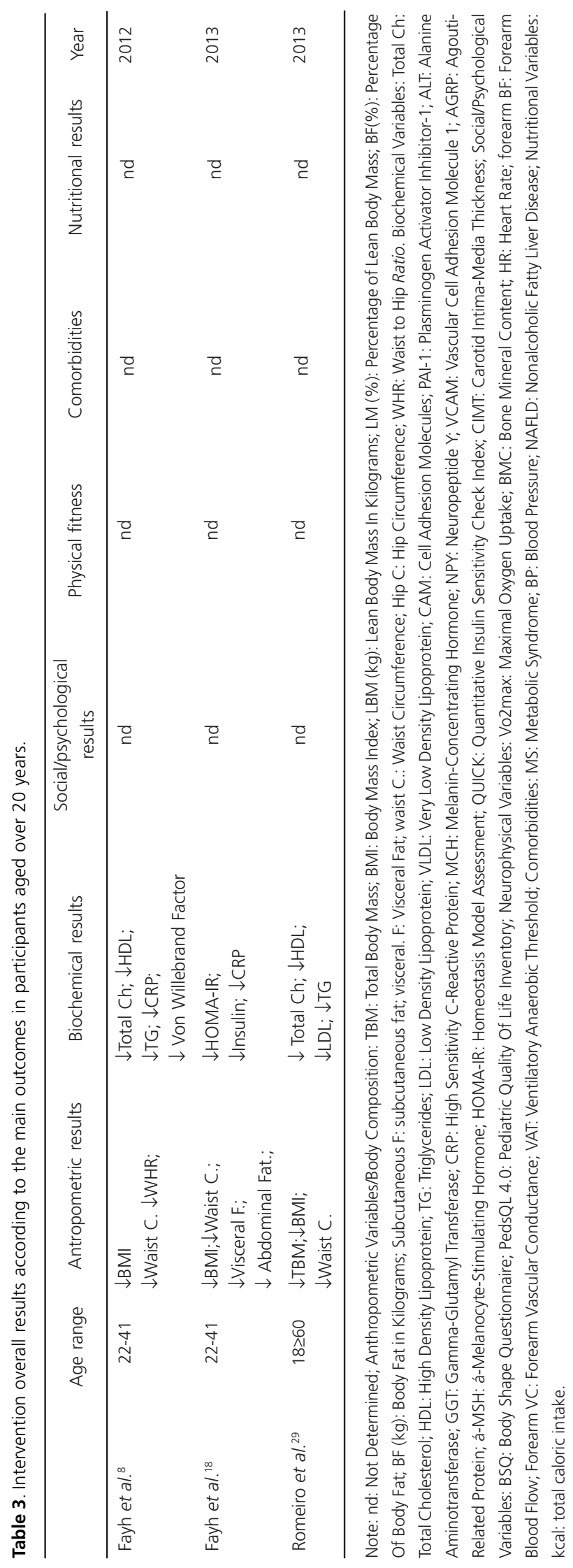


interventions, providing nutritional advices or prescribing and monitoring diets, was also reported in all articles. Among the studies analyzed, 18 reported the participation of psychologists 5,9,11-17,19,22-24,26,30-33, 19 articles reported the participation of a doctor $5,11-15,17,19-27,30,31,33$, and only 1 reported the participation of a nurse $^{11}$, and a physiologist ${ }^{21}$. Seventeen studies ${ }^{5,11-15,17,19-24,26,30,31,33}$ involved the widest range of health fields (physical education, nutrition, psychology, and medicine).

The age of participants in those studies ranged from 6 to 60 years. Of the 26 studies reviewed, 23 involved children and adolescents $5,9,11-17,19-28,30-33$. Offering treatment for these populations is of great importance due to the risk of obesity persisting into adulthood, as well as risk factors for chronic Non-Communicable Diseases (NCD) and possible health problems ${ }^{35}$. Only 3 studies involved adult subjects 8,18,29.

With respect to the main results of those studies, it was observed that all 26 articles reviewed had an impact on anthropometric parameters, 10 on physical fitness parameters, 16 on biochemical parameters, 10 on the present comorbidities, 6 on nutritional parameters, and 4 on psychological/social aspects, as shown in table 2 and 3 below.

In the majority of those studies (88.0\%), the samples were composed of adolescents aged 06-19 years. Most studies were carried out in the Southern and Southeastern regions of the country; a few were carried out in the Central and Northeastern regions and none in the Northern region. Overall, considering the prevalence of obesity and its associated problems, it can be said that there are few treatment programs with multidisciplinary approach since it was found that there are few health care centers that offer this kind of treatment for obesity. These centers provided treatment to a total of 1,372 people, which is low considering the prevalence of overweight (52.5\%) in the Brazilian population ${ }^{3}$. Moreover, the adult population has received disproportionately fewer benefits from these treatments; there were only three studies published over the 10 year-period investigated, which reported that a total of 349 people were submitted to the multidisciplinary treatment.

All articles included allied health fields involved in the interventions, such as, physical education and nutrition, present in 25 studies, and psychology and medicine reported in in 18 studies.

The order of participation of these fields did not influence the treatment results because the treatments had a multidisciplinary approach, and therefore they produced significant positive effects on the variables, regardless of the fields involved.

Seven out of the 26 studies contained control groups, which received treatment for at least 3 months. Most studies adopted an experimental and descriptive approach, and $26.9 \%$ of the articles selected reported 12 monthinterventions.

There was a wide variety of physical training programs, including aerobic training, calisthenics, recreational activities, and recreational sports. The data of several physical exercises described in the methodology of those studies were difficult to interpret, mainly the recreational activities; however, this type of exercise was preferred by the participants. There was no difference in the type of physical exercises used for children and adults.

DISCUSSION

Obesity is considered a public health problem, which, in addition to being highly prevalent, is a risk factor for many chronicdegenerative diseases. Taking into account that the etiology of obesity includes the contribution of several dietary, psychosocial, and environmental factors associated with genetic predisposition ${ }^{34}$, intervention programs including physical exercises, nutritional and psychological counseling, and clinical follow-up have been found to be very effective 
for weight control and for the control of obesityrelated comorbidities ${ }^{19}$.

Relevant information related to the outcomes of multidisciplinary obesity treatments in Brazil - including at least two different health fields - from studies that were published in the scientific literature from 2005 onwards were analyzed descriptively. A total of 29 articles were retrieved and reviewed, among which 16 were selected from the PubMed, 6 from the SciELO, and 7 from the Lilacs databases, but 3 were duplicate copies.

The most important effects of the multidisciplinary treatment on the population investigated include improvements in the anthropometric parameters, such as the reduction in Total Body Mass (TBM) 5, 11,13-16,20-24,26-28,30, Body Mass Index (BMI) 8,9,11-18,20-28,30,31,33, and body fat $(\% \text { or } \mathrm{Kg})^{5,9,11-15,17,19-22,24,26,27,30,32}$. These results are consistent with those from interventions performed in other countries. In a study with adolescents of both genders in Germany, Prado et $a{ }^{36}$ found a significant reduction in body weight, BMI, and body fat after a nine- month intervention.

Costa et al. ${ }^{47}$ found that improvements in the biochemical parameters and moderate weight loss, especially abdominal fat loss, reduced cardiovascular risk in obese individuals, showing that the treatment was successful.

With regard to the anthropometric variables and body composition, except for 4 studies ${ }^{12,17,19,25}$, the treatments reported in all other articles was able to significantly reduce the body mass in the population studied, regardless of the type of intervention. Freitas et al. ${ }^{19}$ were the only authors who did not find a reduction in BMI; however, they reported a reduction in the body fat $(\%$ and $\mathrm{kg})$ and an increase in fat-free mass $(\mathrm{kg})$.

In the studies involving adults ${ }^{7,18,29}$, there were improvements in the anthropometric and biochemical parameters, especially a reduction in $\mathrm{BMI}$ and in the lipid and glycemic profiles. In all articles reviewed, there was no difference between the results of the studies with adolescents and those of the studies with adults in terms of the psychological, anthropometric, and biochemical variables and the nutritional profile.

Among the interventions with more effective results regarding body mass reduction, the study by Ackel-D'Elia et al. ${ }^{11}$ stands out, in which 72 adolescents aged 15-19 years participated in a multidisciplinary program (physical education, nutrition, medicine, and psychology) for obesity control in the city of São Paulo. The study compared, among other variables, the reduction in body mass in three different groups for six months. The individuals who participated in the intervention were subjected to a protocol of combined aerobic and resistance training and had weight loss of $-8.14 \pm 4.17 \mathrm{~kg}$.

Of the 26 articles analyzed, 11 reported differences in waist circumference measurements $8,9,12,14,17,21,22,29,30,32,33$, 3 reported a reduction in the hip circumference ${ }^{12,18,33}$, and only 1 reported a reduction in the waist to hip ratio ${ }^{18}$ and in the arm circumference ${ }^{33}$. All of the interventions described in those articles included the participation of physical education professionals in the design and implementation of exercise programs, which emphasizes the importance of this type of intervention for the control of body parameters that predispose to metabolic diseases. Reduction in abdominal fat lowers the risk of cardiometabolic diseases such hypertension, diabetes mellitus, and dyslipidemia ${ }^{35}$.

Visceral fat reduction was reported in 9 studies $^{13-16,18,22-24,30}$ and subcutaneous fat reduction in 5 studies $13,14,16,22,30$. These findings are especially important due to the fact that fat, especially visceral fat, secrete adipokines, which are associated, directly or indirectly, with processes that contribute to atherosclerosis, hypertension, insulin resistance, diabetes type 2 , and dyslipidemia, explaining the link between adiposity, metabolic syndrome, and cardiovascular diseases ${ }^{37}$. 
As for the results of the biochemical variables, 16 of 26 studies described the interventions' results 5,8,11-16,18,21-24,28-30. Ghrelin and leptin levels increased in 4 studies $^{5,11,16,24}$. Obesity has recently been associated with an increase in circulating levels of leptin due to increased fat deposition, leading to peripheral leptin resistance and a decrease in ghrelin levels, which is involved in the regulation of food intake and energy balance, stimulating appetite, increasing lipogenesis and adipogenesis, and reducing the metabolic rate ${ }^{16-38}$.

Dâmaso et al. ${ }^{16}$ specifically evaluated the effects of a multidisciplinary intervention on plasma levels of ghrelin and leptin, visceral adiposity, and Nonalcoholic Fatty Liver Disease (NAFLD) in obese adolescents. After 3 months of intervention, there were significant differences in all of these parameters. The authors argue that the implementation of a program with nonsystematized physical activities for 60 minutes in subjects with hyperleptinemia is effective in the short-term regulation of the parameters evaluated.

With regard to the lipid profile, the studies reviewed reported reduction in total cholestero|8,12-14,22,28,29-30, Very Low Density Lipoprotein (VLDL) level24, Low Density Lipoprotein (LDL) cholesterol level $14,22,29,30$, and triglyceride leve $8,12,15,21,22,28$ and an in increase in High Density Lipoprotein (HDL) level ${ }^{13,21,28-30}$. However, some of them found conflicting results.

Fayh et al. ${ }^{8}$ carried out a study with 35 adults (22-41 years), and found that their serum HDL cholesterol lowered significantly. The authors believe that such reduction is associated with the total cholesterol reduction and that it was enough to prevent metabolic diseases. Similarly, Romeiro et al. ${ }^{29}$ found lower HDL cholesterol levels after an eight-month multidisciplinary intervention in adults (18>60 years). Despite also finding a significant difference in total cholesterol levels, these authors explained that these results are due to ineffectiveness of the training protocol adopted to increase this lipoprotein.
The results of Campos et al. ${ }^{13}$ demonstrated a reduction in Plasminogen Activator Inhibitor-1 (PAI-1), which is in agreement with the findings of Sanches et al. ${ }^{30}$. It is known that increased levels of PAI-1 is a risk factor for thrombus formation and rupture of unstable atherogenic plaques, besides changing the fibrinolytic balance due to inhibition of plasmin production, thus contributing to the remodeling of vascular architecture and aterosclerotic process ${ }^{37}$. Studies in obese individuals have found an association between higher levels of PAI-1 and other metabolic disorders, such as hyperinsulinemia, hyperglycemia, fasting hypertriglyceridemia, high LDL cholesterol levels, and hypercoagulable state ${ }^{39}$.

Mello et al. ${ }^{22}$ evaluated the effects of a 12-month interdisciplinary weight loss program on the reduction in the risk of atherosclerotic disease by investigating Common Carotid Artery Intima-Media Thickness (CCA-IMT) and the association between insulin resistance and/or inflammation (measured by the inflammatory markers Plasminogen Activator Inhibitor 1 and adiponectin). The program promoted weight loss followed by a significant improvement in insulin levels, Homeostasis Mode Assessment - Insulin Resistance (HOMA-IR), lipid profile, and inflammatory state and a significant decrease in CCA-IMT. The authors concluded that the improvement in HOMA-IR is an independent predictor of CCA-IMT in the population they studied.

As for the psychological and social variables, only 4 studies described the results associated with improvements in psychological and social variables in the population studied ${ }^{19,24,25,31}$. In the articles reviewed, the participation of psychologists in the intervention consisted mostly of weekly or bi-weekly group activities for 1 hour, in which these professionals addressed issues relevant to the programs. When necessary, the participants were referred to individual treatment.

Sapienza et al. ${ }^{31}$ described the effects of a psychological intervention, with parental guidance, on the social competence and reduction in BMI 
of 39 obese adolescents who participated in a 9month multidisciplinary intervention program (including the fields psychology, nutrition, and physical education) implemented for weight loss and control. The participants were divided into three groups: complete experimental group (concomitant psychological intervention for adolescents and their parents); simple experimental group (psychological intervention for parents); and control group (without psychological intervention). After the completion of the program, BMI reduction was higher in adolescents in the first two groups as compared with the control group and, different from what was expected, the group of adolescents in which the parents received psychological intervention the had higher scores in the Child Behavior Checklist $(\mathrm{CBCL})$, and they were perceived as more socially competent by their parents, demonstrating the importance of parents' participation in weight loss programs.

The presence of several different professionals working together provides substantial benefits to the participants. Psychological intervention in multidisciplinary treatments, according to Niet et al. ${ }^{45}$, contributes to weight loss, leading to less behavioral problems and higher levels of social competence in adolescents. Programs for developing self-control, lead to changes such as healthier lifestyles, better food choices, and an increased level of physical activity, as reported by Riggs et a/ ${ }^{46}$.

Freitas et al. ${ }^{19}$ analyzed the effects of a multidisciplinary intervention on body image dissatisfaction among obese adolescents. Thirtyfour subjects aged 12-19 years underwent a multidisciplinary intervention including, nutritional and psychological counseling, clinical follow-up, and physical exercises. The authors used a Body Shape Questionnaire (BSQ) to evaluate body image dissatisfaction. This questionnaire was composed of questions about body image dissatisfaction and concerns about body measurements. The participants were classified as satisfied and dissatisfied based on their score.
After 12 weeks of intervention, there was a reduction in the BSQ scores. It is worth mentioning that although there was no reduction in body mass and BMI, the adolescents showed decreased body image dissatisfaction. Therefore, the authors argue that obese adolescents satisfied with their body have a positive self-concept and high self-esteem, which positively influence their behavior and personal experiences, making them more motivated to adhere to intervention programs, especially in the long run.

Poeta et al. ${ }^{25}$ found an improvement in the emotional domain of 16 children who completed a multidisciplinary program after 3 months of an intervention for obesity treatment, even without the participation of a psychologist. This parameter was measured using the Pediatric Quality of Life Inventory (PedsQL Ferson 4.0 Lyon, France).

With regard to physical fitness, 10 out of the 26 articles reviewed evaluated physical fitness changes in the subjects studied ${ }^{9,12,13,17,21,25-28,32}$. In most of them $9,12,17,21,26,28$, the subjects showed an increase in Volume de Oxigenio Máximo (Vo2max, Maximal Oxygen Uptake). One article ${ }^{27}$ reported an increase in Ventilatory Anaerobic Threshold (VAT). The following findings were also reported: decreased resting heart rate was also reported ${ }^{7,21,26,28,32}$, decreased maximum heart rate $^{21}$, increased heart rate variability ${ }^{17}$, increased heart rate recovery ${ }^{27}$, increased bone mineral content $^{12}$, increased bone mass ${ }^{9}$, improved physical domains ${ }^{25}$, improved aerobic fitness and total exercise time ${ }^{26}$, improved cardiovascular fitness ${ }^{27}$, and increased abdominal strength/ resistance ${ }^{9}$.

In the study carried out by Silva et al. ${ }^{9}, 19$ overweight adolescents of both genders aged 10-18 years underwent a 16-week intervention focusing on changing eating and physical activity behaviors. The intervention resulted in an improved physical fitness, and there was a significant increase in abdominal strength/ resistance, flexibility, and Vo2max. However, eight weeks after the end of the intervention and without maintenance of physical activities, there 
was a significant reduction of in Vo2max, demonstrating the negative impact of the interruption of physical activities on the aerobic fitness in the subjects studied.

It is known that Obesity affects the cardiovascular system. Obese individuals have dysfunctions on the cardiac regulatory mechanisms, which can cause an increase in blood pressure levels and a decrease in muscle blood flow during sympathoexcitatory maneuvers, such as isometric exercise and Cold Pressor Test (CPT), or due to mental stress ${ }^{40}$. Ribeiro et al. ${ }^{28}$ compared the results of resting Heart Rate (HR), forearm blood flow, and forearm vascular conductance between obese and eutrophic children. The authors also investigated whether a multidisciplinary intervention with a low-calorie diet only or with diet plus physical training would have an even greater effect on these parameters in obese individuals. After four months of intervention, the individuals who participated in the diet plus training program showed a significant reduction in resting $\mathrm{HR}$ and an increase in forearm blood flow and forearm vascular conductance.

Obesity treatment has a positive impact on comorbidities associated with overweight. A total of twelve articles reported the results for these variables ${ }^{12,13,15-17,21-24,28,30,32}$ in children and adolescents. The prevalence of Nonalcoholic Fatty Liver Disease (NAFLD) decreased in 4 studies ${ }^{13,16,23,24}$ involving individuals aged between 15 and 19 years. This result had a positive impact on this population because if left untreated, NAFLD can lead to cirrhosis of the liver ${ }^{16}$.

Results related to hypertension improvement were presented in 7 articles $12,15,17,21,28,30,32$. Silva et al. ${ }^{32}$ studied the effects of a multidisciplinary intervention on the hemodynamic profile of 19 adolescents aged between 10 and 18 years. After four months of intervention involving different health professionals (medicine, nutrition, psychology, and physical education), the authors found that weight reduction had a positive effect on blood pressure levels, resulting in BP regularization in all subjects, who had been previously classified as hypertensive.
Farah et al. ${ }^{17}$ found significantly lower values for average, systolic, and diastolic blood pressure. Bianchini et al. ${ }^{12}$ and Sanches et al. ${ }^{30}$ found reduced systolic and diastolic blood pressure, and Carianti et al. ${ }^{15}$ and Leite et al. ${ }^{21}$ found a reduction in systolic blood pressure. These results are consistent with those of studies carried out abroad. Hofsteenge et al. ${ }^{41}$ found significant reduction in systolic and diastolic BP levels in the participants (adolescents aged 11-18 years) of a 18-month multidisciplinary program for obesity treatment in Amsterdam, showing the long-term effects of the program.

The decrease in the prevalence of metabolic syndrome was also found 12,15,21,22. Leite et al. ${ }^{21}$ analyzed the effects of physical exercises and nutritional guidance on body composition, physical fitness, lipid profile, and insulin resistance in obese adolescents (aged 10-16 years) with and without metabolic syndrome. After three months of intervention, the risk factors for metabolic syndrome decreased by $72 \%$.

As for the nutritional variables, 6 articles presented results related to improvements in food intake in the population studied ${ }^{14,16,22,23,30,33}$. An overall reduction in daily energy and macronutrient intake was observed.

Silveira et al. ${ }^{33}$ studied, specifically, the impact of a multidisciplinary treatment on the eating habits of 22 adolescents aged 6-16 years in the city of Belo Horizonte (MG). The nutritional intervention was performed on a monthly basis with individual consultation associated with nutritional education groups. Eating behavior was assessed using a semi-quantitative Food Frequency Questionnaire (FFQ), which was administered at the beginning and after the intervention. After three months of intervention, the authors found improvements in all nutritional variables, especially in terms of changes in the dietary macronutrient distribution.

One of the important aspects of a multidisciplinary treatment is the evaluation of the components studied after the end of the 
treatment to verify whether the length of the intervention is enough to cause changes in the lifestyle of individuals. Silva et al. ${ }^{9}$ investigated the effects of a Multidisciplinary Program For Obesity Treatment (MPOT) in 19 overweight adolescents aged $10-18$ years. The program lasted 16 weeks and focused on changing eating and physical activity behaviors with the participation of psychology, nutrition, medicine, and physical education professionals. During the treatment, there were changes in cardiorespiratory fitness and body fat. However, these improvements were not maintained after the intervention, showing that 16 weeks is enough to cause changes in physical fitness and body composition, but these changes do not seem to be incorporated into the new lifestyle of the adolescents.

Similar findings were reported by, Silva et al. ${ }^{32}$ regarding the maintenance of the results after a multidisciplinary treatment for obesity. Despite the reduction in resting heart rate, waist circumference, Body Mass Index (BMI), relative body fat, and lean body mass, the participants significantly regained weight eight weeks after the end of the treatment.

Significant reduction in systolic and diastolic blood pressure were found in the study by Hollar et al. ${ }^{43}$ with 2,494 obese children aged 6-13 years after performing a 1 yearmultidisciplinary intervention. Cattai et al. ${ }^{44}$ demonstrated that a reduction in adiposity, which provides social integration and physical selfperception benefits, can certainly contribute to the promotion of health of these individuals.

The Multidisciplinary Program for Obesity Treatment aims to involve different health care professionals to work together towards a specific goal, a more effective obesity treatment. Carrel et al. ${ }^{42}$ argue that one of the challenges of this type of program is to avoid interruption of physical activities, which can hinder the maintenance of some of the benefits of the program, such as improvements in body composition and cardiorespiratory fitness.
The outcome of a multidisciplinary treatment depends on the professionals and patients involved, especially regarding the persistence and engagement of the participants. Studies have shown that the success of the treatment is strongly associated with readiness to change in lifestyle, i.e., regular physical activities and a balanced diet ${ }^{48}$.

Therefore, based on the data presented in this review, it can be said that a multidisciplinary treatment involving the fields of physical education, psychology, nutrition, and medicine was proved to be effective. These interrelated fields are essential, and, based on importance evidence, they have been recognized by researchers, as a powerful non-drug therapeutic approach for the treatment and prevention of overweight, obesity, and their comorbidities, improving quality of life and reducing risk of mortality. Moreover, it is an effective way of restoring and maintaining people's health, and it should be made available to the population in general and not only to a restricted number of participants in research centers across the country.

\section{CONCLUSION}

Although there is a reasonable number of publications (26) on this topic in the period investigated, the number of publications per year is very low, with an average of 2.6 articles per year.

Moreover, there is a need for more comprehensive and rigorous methodology, which can be verified by: the lack of studies including sampling to select a representative sample; adequate allocation of participants - few studies employed control groups; lack of double-blind studies - most trials included short-length interventions; lack of follow-up studies for longitudinal monitoring of the multidisciplinary treatment effects based on behavior changes; and lack of physical training intensity control to customize the exercise prescription for specific groups. Another finding was the lack of studies focused on the adult population. 
The present systematic review showed that the articles analyzed suggest that physical exercises combined with a multidisciplinary treatment for overweight and obesity are effective in combating obesity and its comorbidities. The benefits reported in the articles analyzed in the present study showed that there were significant improvements in the anthropometric, biochemical, psychological, and social parameters of the subjects involved in those studies.

The results obtained in the studies reviewed show an urgent need for the implementation of this multidisciplinary approach to combat obesity at the national level in several municipalities of the country since it has been proven to be effective for the treatment of obesity.

Evidence presented in the studies analyzed confirms the success of the multidisciplinary obesity treatment program. Therefore, more support should be given and more investment should be allocated for this type of intervention. So far, the study groups and laboratories of public universities are the ones that have the greatest experience in this field and should therefore be valued and prioritized aiming to expanding the range of these interventions seeking the provision of this health care approach to the population in general. Furthermore, further studies are recommended to overcome the biases in the studies reviewed and bridge the gaps in the state-of-the-art multidisciplinary treatment.

\section{CONTRIBUTORS}

AA MENDES, ASD IEKER and CASTRO TF contributed to all stages of conception and design of this study and to the search and organization of scientific articles addressing the topic studied. N NARDO JÚNIOR and AA ALMEIDA JÚNIOR contributed to the critical revision of the manuscript.

\section{REFERENCES}

1. Fandino J, Benchimol AK, Coutinho WF, Appolinario JC. Cirurgia bariátrica: aspectos clínico- -cirúrgicos e psiquiátricos. Rev Psiquiat RS. 2004; 26(1):47-51.

2. Silva G A, Balaban G, Motta ME. Prevalence of overweight and obesity in children and adolescents of different socioeconomic conditions. Rev Bras de Saúde Mater Infan. 2005; 5(1):53-59.

3. Brasil. Ministério da Saúde. VIGITEL Brasil 2014: vigilância de fatores de risco e proteção para doenças crônicas por inquérito telefônico. Brasília: MS; 2014.

4. Instituto Brasileiro de Geografia e Estatística. Pesquisa de orçamentos familiares: 2008-2009. Rio de Janeiro: IBGE; 2010 [acesso 2015 jul 20]. Disponível em: www.ibge.gov.br

5. Prado WL, Oyama LM, Lofrano-Prado MC, Piano A, Stella SG, Nascimento CMO, et al. Alterations in downstream mediators involved in central control of eating behavior in obese adolescents submitted to a multidisciplinary therapy. J Adolesc Health. 2011; 49(3):300-5.

6. Nader PR, Stone EJ, Lytle LA, Perry CL, Osganian SK, Kelder $\mathrm{S}$, et al. Three-year maintenance of improved diet and physical activity: The CATCH cohort. Arch Pediatr Adolesc Med. 1999; 153(7):695-704.

7. Kerbs NF, Jacobson MS, American Academy of Pediatrics Committee on Nutrition. Prevention of pediatric overweight and obesity. Pediatrics. 2003; 112(2):424-30.

8. Fayh APT, Lopes AL, Silva AMV, Reischak-Oliveira A, Friedman R. Effects of $5 \%$ weight loss through diet or diet plus exercise on cardiovascular parameters of obese: A randomized clinical trial. Eur J Nutr. 2012; 52(5):1443-50.

9. Silva DF, Souza LL, Delfino RO, Bianchini JAA, Hintze L, Nardo Junior N. Efeitos de um programa multiprofissional de tratamento da obesidade e de sua cessação sobre a aptidão física relacionada à saúde de adolescentes. Rev Educ Fis. 2012; 23(3):399-410.

10. Farias ES, Paula F, Carvalho WRG, Gonçalves EM, Baldin AD, Guerra-Júnior G. Efeito da atividade física programada sobre a composição corporal em escolares adolescentes. J Pediatr. 2009; 85(1)28-34.

11. Ackel-D'Elia C, Carnier J, Bueno Jr CR, Campos RM, Sanches PL, Clemente AP, et al. Effects of different physical exercises on leptin concentration in obese adolescents. Int J Sports Med. 2014; 35(2):164-71.

12. Bianchini JAA, Silva DF, Nardo CCS, Hernandes IDRCF, Nardo Junior N. Multidisciplinary therapy reduces risk factors for metabolic syndrome in obese adolescents. Eur J Pediatr. 2013; 172(2):215-21.

13. Campos RMS, Piano A, Silva PL, Carnier J, Sanches $\mathrm{PL}$, Corgosinho FC, et al. The role of pro/anti- 
inflammatory adipokines on bone metabolism in NAFLD obese adolescents: Effects of long-term interdisciplinary therapy. Endocrine. 2012; 42(1):46-56.

14. Campos RMS, Masquio DC, Corgosinho FC, Carvalho-Ferreira JP, Molin Netto BD, Ackel-D’Elia $C$, et al. Low vitamin D intake is associated with increase in cardiovascular risk factors in obese adolescents. Endocr Regul. 2014; 49(1):11-9.

15. Carianti DA, Mello MT, Prado WL, Tock L, Siqueira KO, Piano A, et al. Short-and long-term beneficial effects of a multidisciplinary therapy for the control of metabolic syndrome in obese adolescents. Metabolism. 2007; 56(9):1293-300.

16. Dâmaso AR, Tock $L$, Tufik $S$, Prado WL, Stella SG, Fisberg $\mathrm{M}$, et al. Tratamento multidisciplinar reduz o tecido adiposo visceral, leptina, grelina e a prevalência de esteatose hepática não alcoólica (NAFLD) em adolescentes obesos. Rev Bras Med Esp. 2006; 12(5):263-7.

17. Farah BQ, Ritti-Dias RM, Balagopal PB, Hill JO, Prado WL. Does exercise intensity affect blood pressure and heart rate in obese adolescents? A 6month multidisciplinary randomized intervention study. Pediatr Obes. 2014; 9(2):111-20.

18. Fayh APT, Lopes AL, Fernandes PR, Reischak-Oliveira A, Friedman. Impact of weight loss with or without exercise on abdominal fat and insulin resistance in obese individuals: A randomised clinical trial. $\mathrm{Br} J$ Nutr. 2013; 110(03):486-92.

19. Freitas CRM, Prado MCL, Gomes PP, Almeida NCN, Ferreira MNL, Prado WL. Efeito da intervenção multidisciplinar sobre a insatisfação da imagem corporal em adolescentes obesos. Rev Bras Ativ Fís Saúde. 2013; 17(5):449-56.

20. Gomes PP, Silva HJG, Lira CTC, Lofrano-Prado MC, Prado WL. Efeitos de diferentes intensidades de treinamento aeróbio sobre a lipemia de adolescentes obesos. Rev Bras Ativ Fís Saúde. 2014; 18(6):761-70.

21. Leite N, Milano GE, Cieslak F, Lopes WA, Rodacki A, Radominski RB. Effects of physical exercise and nutritional guidance on metabolic syndrome in obese adolescents. Braz J Phys Ther. 2009; 13(1):73-81.

22. Mello MT, Piano A, Carnier J, Sanches PL, Corrêa FA, Tock $L$, et al. LongTerm effects of aerobic plus resistance training on the metabolic syndrome and adiponectinemia in obese adolescents. J Clin Hypert. 2011; 13(5):343-50.

23. Piano A, Tock L, Carnier J, Oyama LM, Nascimento CMO, Martinz AC, et al. Negative correlation between neuropeptide Y/agouti-related protein concentration and adiponectinemia in nonalcoholic fatty liver disease obese adolescents submitted to a long-term interdisciplinary therapy. Metabolism. 2010; 59(5):613-19.

24. Piano A, Mello MT, Sanche PL, Silva PL, Campos RMS, Carnier J, et al. Long-term effects of aerobic plus resistance training on the adipokines and neuropeptides in nonalcoholic fatty liver disease obese adolescents. Eur J Gynaecol Oncol. 2012; 24(11):313-24.

25. Poeta LS, Duarte MFS, Giuliano ICB, Mota J. Interdisciplinary intervention in obese children and impact on health and quality of life. J Pediat. 2013; 89(5):499-504.

26. Prado DM, Silva AG, Trombetta IC, Ribeiro MM, Nicolau CM, Guazzelli IC, et al. Weight loss associated with exercise training restores ventilatory efficiency in obese children. Int J Sports Med. 2009; 30(11):821-26.

27. Prado DM, Silva AG, Trombetta IC, Ribeiro MM, Guazzelli IC, Matos LN et al. Exercise training associated with diet improves heart rate recovery and cardiac autonomic nervous system activity in obese children. Int J Sports Med. 2010; 31(12):860-65.

28. Ribeiro MM, Silva AG, Santos NS, Guazzelle I, Matos LNJ, Trombetta IC et al. Diet and exercise training restore blood pressure and vasodilatory responses during physiological maneuvers in obese children. Circulation. 2005; 111(15):1915-23.

29. Romeiro C, Nogueira JAD, Dutra ES, Carvalho KMB. Reducing risk factors in overweight adult users of the family health strategy of the Distrito Federal. Rev Nutr. 2013; 26(6):659-68. http://dx.doi.org/ 10.1590/S1415-52732013000600005

30. Sanches PL, Mello MT, Elias N, Fonseca FAH, Piano A, Carnier J, et al. Improvement in HOMA-IR is an independent predictor of reduced carotid intimamedia thickness in obese adolescents participating in an interdisciplinary weight-loss program. Hypertens Res. 2011; 34(2):232-38.

31. Sapienza G, Schoen T, Fisberg M. Efeitos da intervenção psicológica na competência social de adolescentes obesos. Psic Saúde Doenças. 2014; 15(3):612-22.

32. Silva DF, Bianchini JAA, Nardo Junior N. Tratamento multiprofissional da obesidade e sua cessação em adolescentes: efeitos no perfil hemodinâmico. Motriz Rev Educ Fís. 2013; 19(1):195-206.

33. Silveira AM, Jansen AK, Norton RC, Silva GS, Whyte PPM. Efeito do atendimento multidisciplinar na modificação dos hábitos alimentares e antropometria de crianças e adolescentes com excesso de peso. Rev Méd MG. 2010; 20(3):277-84.

34. Francischi RPP, Pereira LO, Freitas CS, Klopfer M, Santos RC, Vieira P, Lancha Júnior AH. Obesidade: atualização sobre sua etiologia, morbidade e 
tratamento. Rev Nutr. 2000; 13(1):17-28. http:// dx.doi.org/10.1590/S0004-27302003000200003

35. Bianchini JAA, Hintze L, Bevilaqua CA, Dell Agnolo CM, Nardo Junior N. Tratamento da Obesidade: revisão de artigos sobre intervenções multiprofissionais no contexto brasileiro. Arq Ciênc Saúde. 2012; 19(2):9-15.

36. Prado WL, Siegfried A, Dâmaso AR, Carnier J, Piano $A$, Siegfried W. Effects of long-term multidisciplinary inpatient therapy on body composition of severely obese adolescents. J Pediat. 2009; 85(3):243-48.

37. Hermsdorff HHM, Monteiro JBR. Gordura visceral, subcutânea ou intramuscular: onde está o problema? Arq Bras Endocrinol Metab. 2004; 48(6):803-11 .

38. Negrão AB, Licinio J. Leptina: o diálogo entre adipócitos e neurônios. Arq Bras Endocrinol Metab. 2000; 44(3):205-14.

39. Wajchenberg BL. Subcutaneous and visceral adipose tissue: Their relation to the metabolic syndrome. Endocr Rev. 2000; 21(6):697-738.

40. Fernandes PROF, Lira FAZ, Borba VVL, Costa MJC, Trombeta IC, Santos MSB, et al. Vitamina C restaura pressão arterial e a resposta vasodilatadora no antebraço em crianças obesas. Arq Bras Cardiol. 2011; 96(6):490-7.

41. Hofsteenge GH, Chinapaw MJM, Waal HAD, Weijs PJM. Long-term effect of the Go4it group treatment for obese adolescents: A randomised controlled trial. Clin Nutr. 2014; 33(3):385-9.

42. Carrel AL, Clark RR, Peterson S, Eickhoff J, Allen DB. School-based fitness changes are lost during summer vacation. Arch Pediatr Adolesc Med. 2007, 161(6):561-4.

43. Hollar D, Messiah SE, Lopez-mitnik G, Hollar TL, Almon M, Agatston AS. Healthier options for public schoolchildren program improves weight and blood pressure in 6- to 13-year-olds. J Am Diet Assoc. 2010; 110(2):261-7.

44. Cattai GBP, Rocha FA, Hintze LJ, Pagan BGM, Nardo Junior N. Programa de tratamento multiprofissional da obesidade: os desafios da prática. Ciênc Cuid Saude. 2008; 7(Supl. 1):121-6.

45. Niet J, Timman R, Rokx C, Jongejan M, Passchier J, Akker E. Somatic complaints and social competence predict success in childhood overweight treatment. Int J Pediatr Obes. 2011; 6(2-2) 472-9. http://dx. doi. org/10.3109/17477166.2011.575145

46. Riggs NR, Sakuma KL, Pentz MA. Preventing risk for obesity by promoting self-regulation and decision-making skills: Pilot results from the PATHWAYS to health program (PATHWAYS). Eval Rev. 2007; 31(3), 287-310. http://dx.doi.org/10.11 77/0193841X06297243

47. Costa PRF, Assis AMO, Silva MCM, Santana MLP, Dias JC, Pinheiro SMC, et al. Mudança nos parâmetros antropométricos: a influência de um programa de intervenção nutricional e exercício físico em mulheres adultas. Cad Saúde Pública. 2009; 25(8):1763-73.

48. Cooper Z, Fairburn CG, Hawker DM. Cognitive behavioral treatment of obesity. New York: Guilford Press; 2003.
Received: January 20, 2016 Final version: July 4, 2016 Approved: August 24, 2016 